\title{
The effect of hardiness on symptoms of insomnia during a naval mission
}

\author{
Morten Nordmo, Sigurd William Hystad, Sverre Sanden, Bjørn Helge Johnsen
}

Department of Psychosocial Science, Faculty of Psychology, University of Bergen, Norway

\begin{abstract}
Background: Sleep is increasingly being recognised as important for the health and well-being of sailors. The aim of the current study is to investigate the relationship between hardiness and reported insomnia-symptoms in a maritime military setting during a 4-month counter piracy naval mission in the Gulf of Aden. Materials and methods: A sample of 281 officers, sailors, and enlisted personnel were measured on levels of hardiness before the mission. The participants were split into low and high hardiness groups based on the group level mean. Insomnia-symptoms were measured before, midway and at the end of the mission. Results: The results showed a significant main effect of time and a significant main effect of hardiness. The crew experienced the most insomnia symptoms in the middle of the mission and the high hardy group experienced less insomnia symptoms, in total, during the mission. There was also found a significant interaction effect of time and hardiness. The high hardiness group experienced less insomnia symptoms before and towards the end of the mission.

Conclusions: The results indicate that high levels of hardiness may be a protective factor between the stressors of a naval mission and symptoms of insomnia.
\end{abstract}

(Int Marit Health 2017; 68, 3: 147-152)

Key words: hardiness, resilience, insomnia, sleep, health, navy, vessel

\section{INTRODUCTION}

Modern naval missions place a heavy toll on the individual sailor. To achieve success, the personnel on a naval vessel work, sleep and live in a complex system of stressors and demanding situations [1]. The crew needs to be alert, even when they are not on duty. This demanding situation has several consequences. One of them is reduced sleep quality and quantity [2]. Sleep has an important function in performance, cognition and motor functions [3]. In addition to this, recent findings in post-traumatic stress disorder (PTSD) research indicate that disturbed sleep is a core feature in the development of PTSD [4]. This makes sleep and insomnia important variables in both operational research and naval maritime industry. This study aims to uncover the basis for resiliency factors that contribute to different levels of insomnia symptoms on a naval mission.

\section{SLEEP, FATIGUE AND MARITIME HEALTH}

Fatigue at sea is increasingly being recognised as a risk factor in naval maritime industry [5]. Stress, workload and sleep problems have been identified as important contributors to reductions in health, safety and motivation [5]. In particular, sleep has a robust relationship with the safety and welfare of seafarers and much effort goes into managing sleepiness and fatigue. A recent rapport [5] concludes that sleepiness and fatigue may be significant contributing factors in accident causation, which can result in injuries, pollution and damage to property as well as company reputation. A study found differences between officers' ratings of actual sleep and ideal sleep length [5]. The trend was most significant for captains and during high intensity port-work. In addition, sleep quality and quantity decreased over time. One way to study effects of maritime operations on sleep is to conduct research on naval personnel. Naval personnel 
are screened and selected based on a lack of somatic and psychological disorders that could act as comorbidity factors to sleep problems.

Modern naval warfare presents similar challenges to sleep. Similar to civilian vessels, a modern naval vessel is comprised of sailors, officers and enlisted personnel working and living in a complex system of interacting stressors $[2,6]$. These stressors affect the operational capability of the crew. Lack of sleep, challenging work conditions, extreme temperatures, uncertainty and isolation contribute to make modern naval missions challenging for the individual [1]. Lack of sleep or a disturbed sleep cycle is a distinct stressor [4]. The working conditions of a modern naval ship may entail long periods without sleep [2, 7]. The sleep environment on board may feature several physical stimuli, which affect sleep quality negatively. They include movement, noise and exposure to blue light. The brain is sensitive to light from the blue spectrum (450-495 nm) [8]. This type of light is produced by computer screens and the displays on board a modern naval vessel. Long exposure to blue light may disturb wake-sleep cycle and cause symptoms of insomnia [9]. A few studies show how sleep may be impaired during a naval mission. Miller and Nguyen [10] found significant differences in sleep patterns and sleep quality on the aircraft carrier USS John C. Stennis. They also found where the personnel worked on the ship to be the most indicative of sleep quality. This is an indication that environmental variables, light, noise and temperature are key factors. In addition, they also found that crewmembers working shifts and being exposed to light before going to sleep reported the least amount of sleep. In another study on the same aircraft carrier, Sawyer [11] investigated the effects of night shift work and reduced sleep quality effect on mood. He found that age predicted the effect on mood, where the youngest experienced the worst mood.

\section{HARDINESS, HEALTH AND PERFORMANCE}

Of the various resiliency factors thus far identified, a very promising one is the personality disposition hardiness. Kobasa [12] first articulated the concept in 1979, and since then a growing body of literature suggests that persons high in hardiness, marked by a strong sense of commitment, control, and challenge, tend to remain healthy under stress compared to those who are low in hardiness. The dimension of commitment refers to an ability to feel committed to the activities in life and to seek involvement rather than withdrawal. The dimension of control refers to the belief that one can control or influence the course of events, and the dimension of challenge refers to a belief that change rather than stability is the normative mode of life, and that change, whether positive or negative, provides an opportunity for personal growth [13].
The question of how hardiness operates to promote health and performance is not entirely clear, but several suggestions have been offered. According to Kobasa [14] the effects of hardiness on mental health are mediated in part by cognitive appraisal mechanisms. Hardiness is associated with a tendency to perceive potentially stressful circumstances in a less threatening manner. In support of this view, empirical evidence exists that high hardy individuals appraise events as less stressful and more tolerable, compared to low hardy individuals [15]. According to Kobasa et al. [16], the adaptive cognitions related to hardiness should also result in decreased sympathetic arousal in response to a potential threat. Given that hardy individuals are less likely to appraise an event as threatening, they should presumably exhibit less physiological arousal relative to less hardy individuals when confronting the same stimuli [17]. Lastly, it has been proposed that differing levels of hardiness operate through different ways of coping. High hardiness individuals are more likely to face challenging and demanding situations with a task oriented coping style [18]. Johnsen et al. [18] found that soldiers with a task focused coping style were more resilient to operational stressors.

\section{HYPOTHESES}

Although limited, there are some studies indicating that hardiness may affect sleep quality and symptoms of insomnia during a military mission. Research into the effect of shift work find that a high level of hardiness is associated with fewer negative effects [19]. This indicates that less than optimal sleeping conditions affect individuals differently, based on their personal disposition. Natvik et al. [20] found that hardiness was negatively associated with insomnia symptoms and sleepiness in both samples of two and three shifts. Although these samples are from different job context and not operative professions, the results are noteworthy, given that the crew of modern naval vessels also work in shifts [2]. Thus, we hypothesize a main effect of hardiness, where higher levels of hardiness are associated with less insomnia symptoms before, during and towards the end of the mission.

Hypothesis 1. There is a significant main effect of hardiness level on the sum of insomnia symptoms experienced during the mission.

As we noted above, modern naval missions present several stressors that may yield a significant main effect of time. We predicted that changes in operational tempo, status of the mission, and cumulative effects of exposure to operative stressors would yield significant differences between the three measurement times.

Hypothesis 2. There is a significant main effect of time on symptoms of insomnia.

Finally, we predicted that the lower hardiness group would have a linear increase in insomnia symptoms during 
the mission. Although the sample is a selected group, high in hardiness, using a mean split will isolate the most vulnerable in the lower hardiness group. Based on earlier studies of hardiness and shift work [19, 20], we predicted that this group would show a worsening of insomnia symptoms. In contrast, we predicted that the high hardiness group would show a linear decrease in insomnia symptoms, demonstrating an adaptation to the stressors on board. Thus producing a significant interaction effect of time and hardiness.

Hypothesis 3. There is a significant interaction effect of time and hardiness level.

\section{MATERIALS AND METHODS}

\section{PARTICIPANTS}

This study is part of the longitudinal follow-up of the crew of a Frigate from the Royal Norwegian Navy. The ship was part of the NATO operation "Ocean Shield", and sailed in the Gulf of Aden. Two crews rotated every 2 months, for a total of 8 months. The primary objective of the operation was counter piracy, and guarding sealines of communication. The crew consisted of 281 persons and included 70 sailors, 90 officers and 58 enlisted. Sixty-three persons did not reveal military rank. The data was reduced from 281 to $164(n=164)$ because of missing data on one or more of the measurement intervals.

\section{PROCEDURE}

Data was collected at three intervals for each crew, before, during and towards the end of the mission, hereafter referred to as PRE, MID and END. Demographic information, psychological hardiness and sleep data was registered during training, 4 weeks before the mission (PRE). We then gathered sleep data 8 weeks after the mission started (MID). Lastly, we gathered sleep data on the last part of the mission, 16 weeks after the mission started (END). The data is part of the individual follow-up of combat personnel and is used in the improvement of personnel handling after international operations. The participants of this study were informed of the purpose of the study. The participants signed an informed consent form.

\section{MEASUREMENTS}

Hardiness. We measured psychological hardiness with a tested and validated Norwegian translation of the 15-item Dispositional Resilience Scale (DRS-15-R) [21]. DRS-15-R is comprised of three dimensions of hardiness: control, commitment and challenge. Each dimension is measured with five questions in DRS-15-R. The answers are registered on a four-point scale ( 1 = Totally disagree, 2 = Partly disagree, 3 = Partly agree, 4 = Totally agree). DRS-15-R has been used in both military and civilian settings [22]. In an early review of hardiness theory, Funk [23] recommended DRS-15-R as the best measuring device for hardiness. Cronbach's Alfa for the measurement was 0.73 .

Sleep. We measured sleep quality before, during and towards the end of the mission with Bergen Insomnia Scale (BIS) [24]. BIS is a self-report scale consisting of 6 questions regarding sleep quality and symptoms of insomnia. The questions are based on the American Psychiatric Association diagnostic manual and the inclusion criterions for diagnosis of insomnia. The scale consists of 6 items scored on an 8-point scale, which indicates the number of days insomnia symptoms are experienced during a week. The symptoms include difficulty falling asleep and sleepiness during the day. The BIS score varies from zero to 42 . BIS has been validated through subjective sleep-reports and EEG studies in both clinical and norm groups [24]. Cronbach's Alfa coefficient for the BIS measurements was 0.89 .

\section{DESIGN AND STATISTICS}

To identify patterns in a high hardiness sample, we created two groups of hardiness levels based on the mean hardiness score in the sample (mean DRS-15-R scores were 48.79). We defined scores below 49 as lower hardiness $(n=76)$, and scores over $49(n=88)$ as high hardiness. This approach was chosen to investigate the effects of differing levels of hardiness in a sample skewed towards high hardiness. A continuous analysis of the effects of high hardiness would arguably not sufficiently demonstrate key differences between individuals, or groups, given the general trend towards high levels. We performed a longitudinal between-within group analysis of variance (ANOVA) with repeated measurements to determine the main effect of time and the interaction effect of hardiness on insomnia symptoms. We used LSD post hoc tests to investigate significant within-group changes. We also used LSD post hoc tests to determine the between-group difference in the three measurement intervals. The measurements of insomnia symptoms revealed a floor effect and data skewed towards zero. The BIS scores were therefore transformed using a square root conversion.

\section{RESULTS}

Descriptive statistics for DRS-15-R before the mission and BIS measurements before, during and towards the end of the mission are presented in Table 1.

We found a significant main effect of hardiness level on BIS, $F(1,323)=4.359, p=0.038$. The high hardiness group $(M=2.18, S E=0.10)$ scored significantly lower on symptoms of insomnia, compared to the lower hardiness group $(M=2.52, S E=0.11)$. We also found a significant main effect of time on BIS scores, $F(2,85)=4.773, p=0.009$. We found most insomnia symptoms at the mission's midway 
Table 1. Descriptive statistics for 15-item Dispositional Resilience Scale (DRS-15-R) and square root of Bergen Insomnia Scale (BIS). Before, during and towards the end of the mission ( $N=162)$

\begin{tabular}{llllllll}
\hline & Hardiness level & $\mathbf{N}$ & Minimum & Maximum & Mean & SD \\
\hline \multirow{2}{*}{ DRS-15-R } & High & 88 & 49 & 60 & 51.82 & 2.542 \\
& Lower & 76 & 37 & 48 & 44.57 & 2.829 \\
\multirow{3}{*}{ BIS PRE } & High & 88 & 0 & 6.08 & 2.02 & 1.091 \\
& Lower & 76 & 0 & 6.08 & 2.55 & 1.220 \\
BIS MID & High & 88 & 0 & 6.24 & 2.47 & 1.272 \\
& Lower & 76 & 0 & 5.09 & 2.53 & 1.292 \\
\multirow{3}{*}{ BIS END } & High & 88 & 0 & 6.16 & 2.04 & 1.255 \\
& Lower & 76 & 0 & 5 & 2.49 & 1.164
\end{tabular}

SD - standard deviation; PRE - 4 weeks before the mission; MID - 8 weeks after the mission started; END - 16 weeks after the mission started

point. LSD post hoc test showed that the MID measurement $(\mathrm{M}=2.5, \mathrm{SE}=0.1)$ was significantly higher than both the $\operatorname{PRE}(\mathrm{M}=2.28, \mathrm{SE}=0.09 ; \mathrm{p}=0.004)$ and the END measurements $(\mathrm{M}=2.27, \mathrm{SE}=0.95 ; \mathrm{p}=0.005)$ of BIS. The PRE and END measurements of BIS were not statistically different ( $p=0.906)$. We also found a significant interaction effect of hardiness level and time, $F(2,324)=3.363, p=0.036)$.

Figure 1 shows the development of insomnia symptoms during the mission. LSD post hoc test showed that the lower hardiness group scored significantly higher on BIS before $(p=0.004)$ and towards the end of the mission $(p=0.017)$. We found no significant difference on BIS scores between the groups at the midway point of the mission ( $p=0.74)$.

We found no significant within-group changes of insomnia symptoms in the lower hardiness group. However, the within-group changes in the high hardiness group showed a significant increase in BIS scores from PRE to MID $(p=0.0001)$ and a significant decrease from MID to END measurement points $(p=0.001)$.

\section{DISCUSSION}

The results support the study's hypotheses. In line with $\mathrm{H} 1$, the present study found that higher levels of hardiness were associated with lower levels of insomnia symptoms during a naval mission. This is in accordance with previous research on sleep, shift work and hardiness [19]. It is of particular interest that Norwegian sailors experience less insomnia symptoms compared to a random sample of Norwegian nurses. In their research, Flo et al. [19] found a total sum BIS score of 14.45 , compared to our samples non-transformed total BIS scores, PRE: 6.63, MID: 7.89 and END: 6.65. In addition, our samples total mean BIS score is also lower than a student sample (11.88) and a Norwegian random community sample (10.67) [24]. The difference may be due to the substantial differences in hardiness. The sample of nurses had a mean DRS-15-R score of 31.15 , compared to our sample with a mean score of 48.19 .

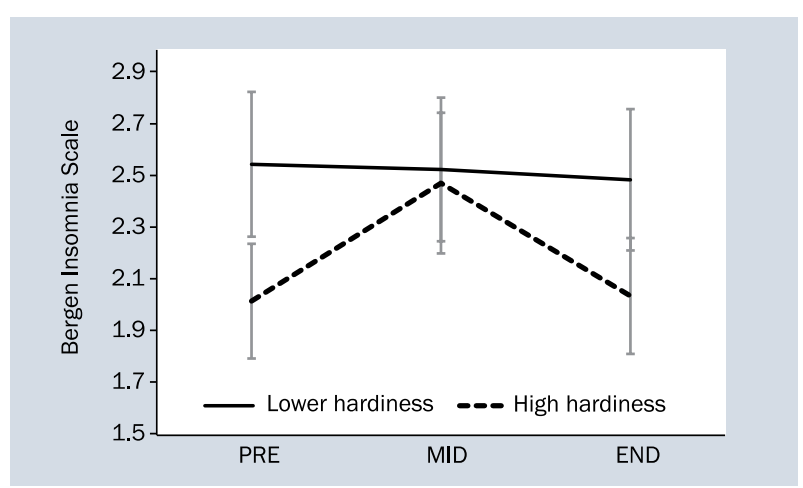

Figure 1. Interaction effect of time and hardiness level on square root of Bergen Insomnia Scale. Error bars are 95\% confidence level; PRE - 4 weeks before the mission; MID -8 weeks after the mission started; END - 16 weeks after the mission started

The main effect of time indicates that a modern naval mission presents differing challenges to sleep at different time points, supporting $\mathrm{H} 2$. This also indicates that the variance in insomnia symptoms is not completely due to static factors and may be affected by operational tempo, challenging mission related events or other changing dynamics aboard the ship. In line with $\mathrm{H} 3$, time and hardiness level produced an interaction effect, but not in the predicted directions. As shown in Figure 1, the middle of the mission presented the highest levels of insomnia symptoms. The lower hardiness group had a high and stable trend of insomnia symptoms, while the high hardiness group increased in their symptoms from before to the middle of the mission, and then showed a significant reduction from the middle towards the end of the mission. This reduction may show the recovery effect of hardy individuals. Hardy sailors show an adaptation over time by returning to pre-mission levels of insomnia symptoms. The non-significant within-group changes in the lower hardiness group indicates that the changes in sleep patterns on board the ship is probably not solely due to time available to sleep, as this would have affected both groups similarly. Rather, the 
pattern in our results seems to indicate that varying levels of sleep quality and quantity on a modern naval mission is partly due to the sailor's personal disposition.

To our surprise, the greatest between-group differences was before the mission. This shows that the training period before the mission might be equal to the actual mission, in terms of sleep problems. This phase of a naval mission is marked by high pre-operational tempo. Preparing the vessel, simulated exercises, and high levels of stress. In addition, there may be worries over the up-coming mission [25]. Here, hardiness may be a buffer to the negative cognitions and heightened arousal that accompanies anxiety and worry [26].

\section{IMPLICATIONS FOR PERSONNEL SELECTION}

Operative situations feature factors that can lead to somatic and psychological health problems [27]. These include situations that threaten lives, health and values. The psychometric approach to personnel selection is contingent on measurements that are standardised, reliable and valid. Our results adds to the growing body of literature, which suggest that hardiness can be a valuable tool in personnel selection [28]. One of the strengths of using measures of hardiness over general personality questionnaires is the sensitivity to resilience factors [21]. Measuring neurotic traits in a high hardiness population may not achieve the same predictive power as using hardiness. Here, there may be a floor effect on levels of neuroticism, but differing levels of hardiness. We found significant differences between groups of hardy and very hardy sailors. This may present a key feature of hardiness theory, predicting health outcomes in high hardiness samples. The magnitude of the effect is small. However, given the nature of the mission and the sample, small but significant changes in sleep problems and symptoms of insomnia may have practical implications for on board functioning, security and performance.

According to a recent report [5], fatigue, stress and heavy workload are also highly typical in civilian maritime industry. Here, crews are under increasing pressure from competition, to increase efficiency, without adding personnel costs [5]. Because of this, there is a growing interest in the maritime industry for mental health research and development of countermeasures to oppose negative effects on crewmembers. There is evidence to suggest that port work is particularly demanding [25], and may be similar to the current study's sample and their pre-mission experience. Three recent studies also conclude that sleep is a major issue for seafarers and managers [5]. The current study has implications in this area as well. Using hardiness measures in naval personnel selection may reduce the negative health, security and motivational effects of reduced sleep quality and quantity in stressful seafarer environments.

\section{LIMITATIONS OF THE STUDY}

The current study has three main limitations. Firstly, the data was also used in a follow-up of the personnel. We cannot rule out the possibility of faking good on measures of insomnia. In addition, presenting a hardy personality may be perceived by the participants to increase the probability of being selected for later missions. Secondly, using a mean split may have introduced unintended patterns in the results. We have not controlled for between-group differences in noise exposure, military rank, gender or other group differences. Lastly, the study lacks objective measures of sleep. Both measures of hardiness and sleep are subjective and we cannot rule out the possibility of general response trends, based on individuals' differing levels of negative affect, influencing the results. However, recent reviews of hardiness research finds that hardiness has predictive power, when controlling for neuroticism [29].

\section{CONCLUSIONS}

The current study explored the relationship between psychological hardiness and symptoms of insomnia during a 4-month counter piracy naval mission in the Gulf of Aden. The results show that higher levels of hardiness are associated with lower levels of insomnia symptoms before and towards the end of the mission.

\section{REFERENCES}

1. Oldenburg M, Jensen HJ, Latza U, et al. Seafaring stressors aboard merchant and passenger ships. Int J Public Health. 2009; 54(2): 96-105, doi:10.1007/s00038-009-7067-z, indexed in Pubmed: 19288290.

2. Sunde E, Bråtveit M, Pallesen S, et al. Noise and sleep on board vessels in the Royal Norwegian Navy. Noise Health. 2016; 18(81): 85, doi:10.4103/1463-1741.178481, indexed in Pubmed: 26960785.

3. Harrison Y, Horne JA. The impact of sleep deprivation on decision making: a review. J Exp Psychol Appl. 2000; 6(3): 236-249, doi: 10.1037//1076-898x.6.3.236, indexed in Pubmed: 11014055.

4. Spoormaker VI, Montgomery P. Disturbed sleep in post-traumatic stress disorder: secondary symptom or core feature? Sleep Med Rev. 2008; 12(3): 169-184, doi: 10.1016/j.smrv.2007.08.008, indexed in Pubmed: 18424196.

5. Jepsen JR, Zhao Z, Szymanski K, et al. Project MARTHA. The Final Report. In Project Martha. the Final Report. 2017.

6. Comperatore C, Rivera P, Kingsley L. Enduring the shipboard stressor complex:A systems approach. Aviat, Space Environ Med. 2005; 76: 108-118.

7. Miller NL, Shattuck LG, Matsangas P. Sleep and fatigue issues in continuous operations: a survey of U.S. Army officers. Behav Sleep Med. 2011; 9(1): 53-65, doi: 10.1080/15402002.2011.53399, indexed in Pubmed: 21218294.

8. Viola A, James L, Schlangen L, et al. Blue-enriched white light in the workplace improves self-reported alertness, performance and sleep quality. Scand J Work Environ Health. 2008; 34(4): 297-306, doi: 10.5271/sjweh.1268.

9. Archibald, K. . Effects of noise, temperature, humidity, motion and light on the sleep patterns of the Crew of HSV-2 SWIFT (Doctoral dissertation) Monterey California, 2005. 
10. Miller NL, Nguyen J. Working the nightshift on the USS John C. Stennis: implications for enhancing warfighter effectiveness. Military Medicine. 2003; 188: 242-252.

11. Sawyer T. The effects of reversing sleep-wake cycles on mood states, sleep, and fatigue on the crew of the USS John C. Stennis (unpublished doctoral thesis). Naval Post Graduate School. 2004, doi: 10.1037/e462282006-001.

12. Kobasa SC. Stressful life events, personality, and health: an inquiry into hardiness. J Personality Social Psychology. 1979; 37(1): 1-11, doi: 10.1037/0022-3514.37.1.1, indexed in Pubmed: 458548.

13. Maddi S. The personality construct of hardiness: I. Effects on experiencing, coping, and strain. Consul Psychol J Pract Res. 1999; 51: 83-94, doi: 10.1037/1061-4087.51.2.83.

14. Kobasa SC, Maddi SR, Kahn S. Hardiness and health: a prospective study. J Person Soc Psychol. 1982; 42(1): 168-196.

15. Ghorbani N, Watson PJ, Morris R. Personality, stress and mental health: evidence of relationships in a sample of Iranian managers. Personality Individual Differences. 2000; 28(4): 647-657, doi: 10.1016/s0191-8869(99)00128-2.

16. Kobasa SC, Maddi SR, Puccetti MC, et al. Effectiveness of hardiness, exercise and social support as resources against illness. J Psychosomatic Res. 1985; 29(5): 525-533, doi: 10.1016/00223999(85)90086-8, indexed in Pubmed: 4067890.

17. Wiebe DJ. Hardiness and stress moderation: a test of proposed mechanisms. J Person Soc Psychol. 1991; 60(1): 89, doi: 10.1037/ 10022-3514.60.1.89, indexed in Pubmed: 1995836.

18. Johnsen BH, Laberg JC, Eid J. Coping strategies and mental health problems in a military unit. Military Medicine. 1998; 163(9): 599, indexed in Pubmed: 9753984.

19. Flo E, Pallesen S, Magerøy N, et al. Shift work disorder in nurses-assessment, prevalence and related health problems. PLoS One. 2012; 7(4): e33981, doi: 10.1371/journal.pone.0033981, indexed in Pubmed: 22485153.
20. Natvik S, Bjorvatn B, Moen BE, et al. Personality factors related to shift work tolerance in two- and three-shift workers. Applied Ergonomics. 2011; 42(5): 719-724, doi: 10.1016/j.apergo.2010.11.006, indexed in Pubmed: 21172694.

21. Hystad SW, Eid J, Johnsen BH, et al. Psychometric properties of the revised Norwegian dispositional resilience (hardiness) scale. Scand J Psychology. 2010; 51(3): 237-245, doi: 10.1111/j.14679450.2009.00759.x, indexed in Pubmed: 20028488.

22. Natvik S, Bjorvatn B, Moen BE, et al. Personality factors related to shift work tolerance in two- and three-shift workers. Applied Ergonomics. 2011; 42(5): 719-724, doi: 10.1016/j.apergo.2010.11.006, indexed in Pubmed: 21172694.

23. Funk S. Hardiness: A review of theory and research. Health Psychology. 1992; 11(5): 335-345, doi: 10.1037//0278-6133.11.5.335.

24. Pallesen S, Bjorvatn B, Nordhus IH, et al. A new scale for measuring insomnia: the Bergen Insomnia Scale 1. Perceptual and Motor Skills. 2008; 107(3): 691-706, doi: 10.2466/pms.107.3.691-706, indexed in Pubmed: 19235401.

25. Johnsen BH, Eid J, Birkhaug P, et al. Coping style and sailors perception of their home situation: Effects on psychological readiness during deployment of RNoN vessels in international operations. Int Review Armed Forces Medical Services. 2007; 80(1): 39.

26. Hanton S, Evans L, Neil R. Hardiness and the competitive trait anxiety response. Anxiety, Stress, and Coping. 2003; 16(2): 167-184, doi: 10.1080/10651580021000069416.

27. Jones E, Wessely S. Shell shock to PTSD: Military psychiatry from 1900 to the Gulf War. Psychology Press 2005.

28. Bartone P, Roland R, Picano J, et al. Psychological Hardiness Predicts Success in US Army Special Forces Candidates. Int J Selection Assessment. 2008; 16(1): 78-81, doi: 10.1111/j. 1468-2389.2008.00412.x.

29. Eschleman K, Bowling N, Alarcon G. A meta-analytic examination of hardiness. Int J Stress Management. 2010; 17(4): 277-307, doi: $10.1037 / \mathrm{a} 0020476$. 